\title{
Multi-period fuzzy mean-semi variance portfolio selection problem with transaction cost and minimum transaction lots using genetic algorithm
}

\author{
Mohammad Ali Barati, Mohammad Mohammadi* and Bahman Naderi
}

Department of Industrial Engineering, Faculty of Engineering, Kharazmi University, 15719 - 14911 Tehran, Iran

\begin{tabular}{l}
\hline C H R O N I C L E \\
\hline Article history: \\
Received July 222015 \\
Received in Revised Format \\
Septmber17 2015 \\
Accepted October 242015 \\
Available online \\
October 252015 \\
\hline Keywords: \\
Multi-period portfolio \\
Mean-semi variance \\
Transaction cost \\
Minimum transaction lots \\
Fuzzy theory
\end{tabular}

\section{A B S T R A C T}

Multi-period models of portfolio selection have been developed in the literature with respect to certain assumptions. In this study, for the first time, the portfolio selection problem has been modeled based on mean-semi variance with transaction cost and minimum transaction lots considering functional constraints and fuzzy parameters. Functional constraints such as transaction cost and minimum transaction lots were included. In addition, the returns on assets parameters were considered as trapezoidal fuzzy numbers. An efficient genetic algorithm (GA) was designed, results were analyzed using numerical instances and sensitivity analysis were executed. In the numerical study, the problem was solved based on the presence or absence of each mode of constraints including transaction costs and minimum transaction lots. In addition, with the use of sensitivity analysis, the results of the model were presented with the variations of minimum expected rate of programming periods.

\section{Introduction}

The investment portfolio selection problem is one of the classical issues of the financial world which was first introduced by Markowitz (1959). This problem includes two main and inseparable components of return and risk aimed at maximizing the expected return at a certain level of risk or minimizing the expected risk at a certain level of return. Markowitz (1959), for first time, presented the optimum set of assets model (mean-variance theory). He presented the problem as quadratic programing aimed at minimizing the set of assets variance under the condition that the expected return is a fixed value. The main assumption of this model is that all investors avoid risk. The problem has another functional constraint based on which the sum of ratios of capital involved in assets should equal 1 . In addition, the ratio of capital involved in any asset in the portfolio should be non-negative. The primary model of Markowitz was presented given the normal distribution of returns on assets with the absence of transaction costs and taxes, as well as the ban on short selling and indivisibility of shares. 
In recent years, the need for multi-period portfolio optimization has been emphasized. The goal is to maximize the fortune at the end of a certain period. In such a situation, the decision-maker constantly monitors the market, gathers information about the events taking place in the market and anticipates the future as well. This issue has many financial applications including asset-debt management, index tracking, investment management, organizational investment funds etc.

With multi-period portfolio as a newly-emerged issue, the need for certain factors to make the model more tangible is felt. Transaction cost and minimum transaction lots are among the most important factors. In addition, for the purpose of approximating the issue to the real dominant conditions of the market and given the nature of the parameters which are often ambiguous and uncertain, the problem was inevitably raised in a fuzzy environment.

This paper examined a multi-period model of portfolio selection problem. The problem was addressed as a mean semi-variance model encompassing such functional constraints as minimum transaction lots and transaction cost. After modeling, the above issue was studied taking into account the uncertainty of some parameters in the fuzzy environment, and then a meta-heuristic GA was used to solve the model. Although, with respect to portfolio optimization, there are studies on multi-period models, models with fuzzy parameters, and mean semi-variance models, the combination of all these points along with functional constraints, such as transactions cost and minimum transaction lots have never been analyzed in any of the previous research studies.

\section{A review of the literature}

In this section, studies relevant to portfolio are examined from different perspectives.

\subsection{Single-Period Investment Portfolio}

After the introduction of the mean-variance model by Markowitz which is the basis for single-period investment portfolio selection models, many developments were performed on the model (see, for example, Xia et al., 2000; Giove et al., 2006: Gupta et al., 2008; Yu \& Lee, 2011).

\subsection{Multi-Period Investment Portfolio}

Recently, Li and Ng (2000) provided an optimum analytic solution to multiple-period mean-variance model. They raised the dynamic portfolio selection problem and introduced an analytic model. Having added a constraint called bankruptcy constraint to the model, Wei and Ye (2007) assumed the meanvariance model in multi-period conditions. The model followed the Markov chain and stochastic market conditions. Gülpinar and Rustem (2007) proposed the multi-period mean-variance optimization problem in which the scenario tree was used to include the uncertainty and the occurrence probability of each scenario in the next periods.

Çelikyurt and Özekici (2007) applied the Markov chain to propose several multi-period mean-variance investment portfolio optimization models. Calafiore (2008) targeted risk as a goal so that the function of any decision on the portfolio is to minimize the overall risks in different periods. Including transaction cost in the model, Zhang and Zhang (2009) introduced a new multi-period stochastic optimization model based on conditional at-risk value. Takano and Gotoh (2010) discussed the resolution of multi-period investment portfolio optimization problem through a conditional at-risk value under the nonlinear transaction cost.

Sadjadi, et al. (2011) proposed a fuzzy multi-period investment portfolio with different lending and borrowing rates. Sun, et al. (2011) introduced the multi-period investment portfolio optimization problem with a new algorithm called particles congestion buoyancy optimization and suggested that the new 
algorithm is more efficient than other algorithms. Liu et al. (2012) proposed the multi-period meanelongation investment portfolio in a fuzzy environment and showed that this model preserves a better function than models that do not use elongation as a risk measure.

\subsection{Transaction cost}

WagnerWayne (1990) maintained that failure to include transaction costs leads to the worse solution, thus transaction costs must constitute one of the main concerns of today's portfolio managers. Liu et al. (2012) discussed the portfolio selection problem with the multi-period approach, and considered a number of criteria such as return, transaction cost, risk and skewness of the portfolio. Also, some others such as Takano and Gotoh (2009), Zhang and Zhang (2009), and Zhang et al. (2012) entered transaction cost into the investment portfolio selection problem.

\subsection{Transaction Lots}

Mansini and Speranza (1999) added minimum transaction lots as a constraint to the original model, and offered an innovative way to solve the problem.

\subsection{Fuzzy Models}

For the first time in 1965 following the publication of fuzzy sets by Professor Lotfi Zadeh (Zadeh, 1965), the fuzzy logic appeared in calculations and studies. Due to the uncertain nature of the variables and parameters of the capital markets, the need for using a fuzzy concept was felt in this area. For the first time the fuzzy logic entered portfolio selection problems and related articles and research in the beginning of the 90s. In the following some of these articles are cited.

Sadjadi et al. (2011) proposed a fuzzy linear model that can calculate the amount of investments in assets in different time cycles (Multi-period model). In this paper, the rate of return and the rate of lending or borrowing are presented in the form of triangular fuzzy parameters. It is also assumed that the borrowing rate exceeds the lending rates. Liu et al. (2012) discussed the multi-period portfolio selection problem in a fuzzy environment. They used the TOPSIS method to convert the model into a single-objective one and solved it by genetic algorithm.

Liu et al. (2013) addressed a multi-period portfolio optimization problem while the return, risk and liquidity of the stock were introduced as interval variables. The problem defined was solved using the fuzzy decision theory, the multi-objective programming approach and the improved PSO algorithm.

Li and Xu (2013) proposed a multi-objective model of the portfolio selection problem where the rate of return was calculated in a fuzzy environment and model was presented with three criteria of return, risk and liquidity. In the optimum solution, based on the GA, a method was introduced whose function has been verified in numerical examples as well.

\section{Modeling of the Problem}

In this section, the multi-period portfolio problem is modeled. A multi-period portfolio selection problem is considered with $n$ assets. It is assumed that the investor at the beginning of Period 1 joins the market with the initial wealth $w 1$. The investor plans to allocate his wealth between $n$ risky assets during the $T$ periods. His wealth could be reallocated between $n$ assets at the beginning of each subsequent period. Symbols for the problem are presented below:

$\mathrm{x}_{\mathrm{ti}} \quad$ Weight of asset $i$ in the portfolio in period $t$ 
$\mathrm{x}_{\mathrm{t}} \quad$ Portfolio of period $t$ where: $\mathrm{x}_{\mathrm{t}}=\left(\mathrm{x}_{\mathrm{t} 1}, \mathrm{x}_{\mathrm{t} 2}, \ldots, \mathrm{x}_{\mathrm{tn}}\right)$

$\mathrm{r}_{\mathrm{ti}}$ Expected rate of return on asset $i$ in period $t$

$r_{t} \quad$ Minimum rate of return on the portfoliox ${ }_{t}$ in period $t$

$\mathrm{R}_{\mathrm{Pt}}$ Rate of return on the portfolio $\mathrm{x}_{\mathrm{t}}$ in period $t$

$\mathrm{R}_{\mathrm{Nt}}$ Net rate of return on the portfolio $\mathrm{x}_{\mathrm{t}}$ in period $t$

$\mathrm{W}_{\mathrm{t}}$ Accumulated wealth at the beginning of period $t$

$\mathrm{c}_{\mathrm{ti}} \quad$ Cost of asset $i$ in period $t$

$\mathrm{c}^{\prime}{ }_{\mathrm{ti}} \quad$ Rate of transaction cost of asset $i$ in period $t$

$\mathrm{C}_{\mathrm{t}} \quad$ Total transaction cost of portfolio $x_{t}=\left(x_{t 1}, x_{t 2}, \ldots, x_{t n}\right)$ in period $t$

$\mathrm{y}_{\mathrm{ti}} \quad$ Minimum transaction lots of asset $i$ in period $t$ (Variable integer)

$\mathrm{z}_{\mathrm{ti}} \quad$ Binary variable equal to 1 if asset $i$ in period $t$ is selected

$\mathrm{L}_{\mathrm{i}} \quad$ Lower limit for transaction cost of asset $i$ in each period

$\mathrm{U}_{\mathrm{i}} \quad$ Upper limit for transaction cost of asset $i$ in each period

M Very large number

It is assumed that the investor's objective is to minimize the risk of the assets portfolio. The rate of return on the portfolio in each period must be greater than a predetermined level. Nonetheless, the multi-period portfolio selection problem can be formulated as a mathematical programming model as follows:

$$
\begin{aligned}
& \min \operatorname{Var}^{-}\left(R_{N t}\right)=\sum_{i=1}^{n} x_{t i}^{2} \operatorname{Var}^{-}\left(r_{t i}\right)+2 \sum_{i<j=1}^{n} x_{t i} x_{t j} \operatorname{Cov}^{-}\left(r_{t i}, r_{t j}\right) \\
& W_{t+1}=W_{t}\left(1+R_{N t}\right), \quad t=1,2 \ldots T-1 \\
& R_{N t}=E\left[\sum_{i=1}^{n} x_{t i} r_{t i}\right]-\sum_{i=1}^{n} c^{\prime}{ }_{t i}\left|x_{t i}-x_{t-1, i}\right|, \quad t=1,2 \ldots T \\
& R_{N t} \geq r(t), \quad t=1,2 \ldots T \\
& x_{t i}=\frac{y_{t i} c_{t i}}{\sum_{i=1}^{n} y_{t i} c_{t i}}, \quad t=1,2 \ldots T \\
& \sum_{i=1}^{n} y_{t i} c_{t i} \leq W(t), \quad t=1,2 \ldots T \\
& L_{i}-M\left(1-z_{t i}\right) \leq y_{t i} c_{t i} \leq U_{i}+M\left(1-z_{t i}\right), \quad t=1,2 \ldots T ; i=1,2 \ldots n \\
& \sum_{i=1}^{n} z_{t i} \leq k, \quad t=1,2 \ldots T \\
& \frac{x_{t i} \leq z_{t i} \leq x_{t i}, \quad t=1,2 \ldots T ; i=1,2 \ldots n}{M} \quad t=1,2 \ldots n ; t=1,2 \ldots T \\
& z_{t i} \in\{0,1\}, \quad i=1,2 \ldots n ; t=1,2 \ldots T \\
& x_{t i} \geq 0, \quad t=1,2 \ldots T \\
& y_{t i} \geq 0, I n t e g e r \\
& \quad i=1,2 \ldots
\end{aligned}
$$


In accordance with the theory of mean semi-variance criteria, the investor seeks to determine the best strategy $x_{t}=\left(x_{t 1}, x_{t 2}, \ldots, x_{t n}\right)$ to minimize the semi-variance or Eq. (1); Eq. (2) is the accumulated wealth at the beginning of period t or the amount of capital available in period t; Eq. (3) indicates the net rate of return on the portfolio $x_{t}=\left(x_{t 1}, x_{t 2}, \ldots, x_{t n}\right)$ in the period $t$ that includes two phrases, the former of which is that the mean value of the rate of return and the latter is the transaction cost of portfolio $x_{t} i n$ period t. It is assumed that transaction cost is a $\mathrm{V}$-shaped function of the difference between portfolio of period $\mathrm{t}, x_{t}=\left(x_{t 1}, x_{t 2}, \ldots, x_{t n}\right)$ and $\mathrm{t}-1, x_{t-1}=\left(x_{t-1,1}, x_{t-1,2}, \ldots, x_{t-1, n}\right)$ (Zhang et al., 2012). Eq. (4) ensures that in each period, the portfolio expected return is greater than a minimum certain amount; the weight of each asset in each period is equal to the ratio of transaction cost of that asset to the total transaction cost indicated by Eq. (5); Eq. (6) ensures that in each programming period, the cost of the selected portfolio does not exceed that the available budget in that period; using Eq. (7), the transaction cost of each asset is placed between an upper and a lower limit; Eq. (8) ensures that exactly k assets in the portfolio are selected; Eq. (9) states the relationship between variables $x_{t i}$ and $z_{t i}$; finally Eq. (10), Eq. (11) and Eq. (12) describe the types of variables.

\subsection{Premises of Fuzzy Relations}

Based on Zhang, et al. (2012) relations of trapezoidal fuzzy numbers like $A=(a, b, \alpha, \beta)$ in which the variation interval is $[a, b]$, the left width is $\alpha>0$ and the right width is $\beta>0$, are presented below. If the membership function of the fuzzy number is as follows:

$$
\mu_{A}(x)=\left\{\begin{array}{cc}
1-\frac{a-x}{\alpha} & a-\alpha \leq x \leq a \\
1 & a \leq x \leq b \\
1-\frac{x-b}{\beta} & b \leq x \leq b+\beta \\
0 & \text { otherwise }
\end{array}\right.
$$

Then, set $\gamma$ - of fuzzy number $\mathrm{A}$ is defined as follows:

$$
[A]^{\gamma}=[a-(1-\gamma) \alpha, b+(1-\gamma) \beta], \forall \gamma \epsilon[0,1] \text {. }
$$

The expected value of mean and variance $\mathrm{A}$ is calculated as follows respectively:

$$
\begin{aligned}
& E(A)=\frac{a+b}{2}+\frac{\beta-\alpha}{6}, \\
& \operatorname{Var}(A)=\left[\frac{b-a}{2}+\frac{\alpha+\beta}{6}\right]^{2}+\frac{(\beta+\alpha)^{2}}{72}+\frac{(\beta-\alpha)^{2}}{72} .
\end{aligned}
$$

Also, the upper and lower limits of the semi-variance of fuzzy number Aare calculated as follows respectively:

$$
\begin{aligned}
& \operatorname{Var}^{+}(A)=\left[\frac{b-a}{2}+\frac{\alpha+\beta}{6}\right]^{2}+\frac{\beta^{2}}{18}, \\
& \operatorname{Var}^{-}(A)=\left[\frac{b-a}{2}+\frac{\alpha+\beta}{6}\right]^{2}+\frac{\alpha^{2}}{18}
\end{aligned}
$$

The upper and lower limits of semi-covariance of two fuzzy numbers of $A_{1}=\left(a_{1}, b_{1}, \alpha_{1}, \beta_{1}\right)$, and $A_{2}=$ $\left(a_{2}, b_{2}, \alpha_{2}, \beta_{2}\right)$, are respectively calculated as follows: 


$$
\begin{aligned}
\operatorname{Cov}^{+}\left(A_{1}, A_{2}\right) & =\frac{\left(\beta_{1}+\alpha_{1}\right)\left(\beta_{2}+\alpha_{2}\right)}{36}+\frac{\left(b_{1}-a_{1}\right)\left(\beta_{2}+\alpha_{2}\right)+\left(b_{2}-a_{2}\right)\left(\beta_{1}+\alpha_{1}\right)}{12} \\
& +\frac{\left(b_{1}-a_{1}\right)\left(b_{2}-a_{2}\right)}{4}+\frac{\beta_{1} \beta_{2}}{18} \\
\operatorname{Cov}^{-}\left(A_{1}, A_{2}\right) & =\frac{\left(\beta_{1}+\alpha_{1}\right)\left(\beta_{2}+\alpha_{2}\right)}{36}+\frac{\left(b_{1}-a_{1}\right)\left(\beta_{2}+\alpha_{2}\right)+\left(b_{2}-a_{2}\right)\left(\beta_{1}+\alpha_{1}\right)}{12} \\
& +\frac{\left(b_{1}-a_{1}\right)\left(b_{2}-a_{2}\right)}{4}+\frac{\alpha_{1} \alpha_{2}}{18} .
\end{aligned}
$$

\section{The Problem-Solving Approach}

Genetic algorithm (GA) is inspired by Darwin's theory of evolution as well as genetics based on the survival of the superiors and or natural selection. A common application of GA is presented as an optimizer function. In GAs, the genetic evolution of living organisms is simulated. In the following, the genetic algorithm for the modeling problem is designed.

\subsection{Coding solutions}

According to the model of the problem, each solution to the model and each chromosome in GA can be represented by matrix $X$ and matrix $Y$ respectively.

$X=\left[\begin{array}{cccc}x_{11} x_{12} & \ldots & x_{1 n} \\ x_{21} x_{22} & \ldots & x_{2 n} \\ \vdots & \vdots & \ddots & \vdots \\ x_{T 1} x_{T 2} & \ldots & x_{T n}\end{array}\right], \quad Y=\left[\begin{array}{cccc}y_{11} y_{12} & \ldots & y_{1 n} \\ y_{21} y_{22} & \ldots & y_{2 n} \\ \vdots & \vdots & \ddots & \vdots \\ y_{T 1} y_{T 2} & \ldots & y_{T n}\end{array}\right]$

To convert each chromosome to a solution, the following is taken:

$x_{t i}=\frac{y_{t i} c_{t i}}{\sum_{i=1}^{n} y_{t i} c_{t i}} \quad \forall t, i$

This coding method ensures that $\sum_{i=1}^{n} x_{t i}=1$. Thus one of the problem constraints is automatically during the problem-solving process.

\subsection{Initial solution production}

The initial solution is provided as follows. Matrix elements (genes) or are randomly initialized; due to the constraints of Eq. (7), assuming an asset is selected $z_{t i}=1$, then:

$$
\frac{l_{i}}{c_{t i}} \leq y_{t i} \leq \frac{U_{i}}{c_{t i}}
$$

Therefore, first matrix $Y$ is initialized with respect to Eq. (21) and its being integer. After checking the constraints of the maximum number of assets in each period (Eq. (8)), using the relation between $X$ and $Y$ expressed in the previous section, matrix $Y$ is converted to matrix $X$. If the provided solution does not establish the problem constraints, it is rejected and another solution is provided.

\subsection{Constraint-Handling Method}

When working with meta-heuristic algorithms, at every stage of the solution production, impossible solutions that occur due to a violation of the problem constraints may be encountered. In the literature 
there are several methods to handle the constraints, some of which include: penalty function, repair algorithm, rejection strategy etc.

In the present study, in the initial stage of solution production, when faced with impossible solutions, the rejection strategy is used to produce new solutions in order to produce possible solutions as much as pop at the beginning of the algorithm. However, in the algorithm iterations after the intersection and mutation operators were applied, impossible solutions may occur, in which case the penalty function is used.

\subsection{Fitness Function}

There are different methods to define the fitness function (see Goldberg, 1989). In this algorithm, an exponential fitness function which is defined for chromosome $\mathrm{j}$ as follows is used:

$F_{j}=e^{f_{j}}, \quad j=1,2, \ldots$, pop

where $f_{j}$ is the value of the objective function of the $\mathrm{j}$-th chromosome.

\subsection{Selection Operator}

Using the selection operator, a number of chromosomes in a population of chromosomes are selected for breeding. In this algorithm the roulette wheel method is used where the probability of selecting any solution is tailored to its fitness. According to the fitness function defined in the previous section, the selection probability of chromosome $\mathrm{j}$ is as follows:

$$
p_{j}=\frac{1 / F_{j}}{\sum_{j=1}^{n} 1 / F_{j}}
$$

\subsection{Intersection Operator}

In this algorithm, a type of arithmetic intersection is used, such that a random number is generated as $\theta \epsilon(0,1)$. If $\theta<\mathrm{P}_{c}\left(\mathrm{P}_{\mathrm{c}}\right.$ is the probability of intersection), the intersection operator runs; otherwise, it does not run. Since this process is iterated as much as pop, $\theta *$ pop times the intersection operator is performed on average. However, when the intersection operator should be performed, bearing in mind that $Y_{1}$ and $\mathrm{Y}_{2}$ are the parental chromosomes, two new offspring are produced as follows.

$$
\begin{aligned}
& Y_{1}^{\prime}=\tau Y_{1}+(1-\tau) Y_{2}, \\
& Y_{2}^{\prime}=\tau Y_{2}+(1-\tau) Y_{1},
\end{aligned}
$$

where $\tau$ is a random number in the interval $(0,1)$. In other words, at this type of intersection, the new offspring's genes are a linear combination of parental genes.

\subsection{Mutation Operator}

This operator selects of a gene from a chromosome randomly and then alters the content of that gene. Here $P_{m}$ is defined as the probability of mutation. A chromosome is selected randomly with probability $P_{m}$, the mutation operator is applied on it. If the mutation operator is to be applied, on the genes of the chromosome is selected, then the value of this gene is randomly initialized between zero and one. 


\subsection{Termination Condition Algorithm}

The termination condition of the algorithm is defined based on the number of iteration of the algorithm. For example, the algorithm runs after being iterated 200 times.

\section{Setting the Parameters}

The Taguchi method is used to set the parameters of the GA. To present his experiments, Taguchi, introduced specific groups of orthogonal arrays. In this method, the setting of the parameters based on the variance analysis is known as the concept of signal-to-noise. In this method the signal-to-noise ratio or $\mathrm{S} / \mathrm{N}$ is calculated as follows:

$$
\mathrm{S} / \mathrm{N}=-10 \times \log \left(\frac{1}{n} \sum_{i=1}^{n} y_{i}^{2}\right) \text {, }
$$

where $\mathrm{y}$ is the observed fitness value and $\mathrm{n}$ is the number of observations.

The GA parameters include: population size, intersection rate and mutation rate. Each of the parameters of the algorithm is studied at three levels. The levels of the parameters are presented in Table 1.

\section{Table 1}

Levels Defined For GA Parameters

\begin{tabular}{lccc}
\hline Parameter & Level 1 & Level 2 & Level 3 \\
\hline Population size & 50 & 100 & 150 \\
intersection Rate & 0.6 & 0.7 & 0.8 \\
Mutation probability & 0.1 & 0.2 & 0.3 \\
\hline
\end{tabular}

Since there are 3 levels, the orthogonal array L 18 shown in Table 2, is used provided that the additional columns are removed. Now each time the experiment is conducted 4 times in the levels specified in this array.

Table 2

Orthogonal Array

\begin{tabular}{|c|c|c|c|c|c|c|c|c|c|}
\hline & \multicolumn{8}{|c|}{ Parameters } \\
\hline & & A & B & C & $\mathrm{D}$ & $E$ & $\mathrm{~F}$ & G & $\mathrm{H}$ \\
\hline \multirow{18}{*}{ Experiments } & 1 & 1 & 1 & 1 & 1 & 1 & 1 & 1 & 1 \\
\hline & 2 & 1 & 1 & 2 & 2 & 2 & 2 & 2 & 2 \\
\hline & 3 & 1 & 1 & 3 & 3 & 3 & 3 & 3 & 3 \\
\hline & 4 & 1 & 2 & 1 & 1 & 2 & 2 & 3 & 3 \\
\hline & 5 & 1 & 2 & 2 & 2 & 3 & 3 & 1 & 1 \\
\hline & 6 & 1 & 2 & 3 & 3 & 1 & 1 & 2 & 2 \\
\hline & 7 & 1 & 3 & 1 & 2 & 1 & 3 & 2 & 3 \\
\hline & 8 & 1 & 3 & 2 & 3 & 2 & 1 & 3 & 1 \\
\hline & 9 & 1 & 3 & 3 & 1 & 3 & 2 & 1 & 2 \\
\hline & 10 & 2 & 1 & 1 & 3 & 3 & 2 & 2 & 1 \\
\hline & 11 & 2 & 1 & 2 & 1 & 1 & 3 & 3 & 2 \\
\hline & 12 & 2 & 1 & 3 & 2 & 2 & 1 & 1 & 3 \\
\hline & 13 & 2 & 2 & 1 & 2 & 3 & 1 & 3 & 2 \\
\hline & 14 & 2 & 2 & 2 & 3 & 1 & 2 & 1 & 3 \\
\hline & 15 & 2 & 2 & 3 & 1 & 2 & 3 & 2 & 1 \\
\hline & 16 & 2 & 3 & 1 & 3 & 2 & 3 & 1 & 2 \\
\hline & 17 & 2 & 3 & 2 & 1 & 3 & 1 & 2 & 3 \\
\hline & 18 & 2 & 3 & 3 & 2 & 1 & 2 & 3 & 1 \\
\hline
\end{tabular}


The results of ANOVA are presented in Table 3. As we can observe, the most important factor in determining the performance of this algorithm is population size with a P-value of 0.02 at $5 \%$ significance level. Therefore, the homogeneity of the levels of this parameter is rejected. The levels defined for other parameters are not significantly different.

Table 3

ANOVA of the Algorithm Signal-To-Noise

\begin{tabular}{llllll}
\hline Source & df & Sum of squares & Mean of squares & F & sig \\
\hline Population size & 2 & 0.01845 & 0.009225 & 5.172018 & 0.0261 \\
intersection Rate & 2 & 0.00337 & 0.001685 & 0.944699 & 0.418196 \\
Mutation probability & 2 & 0.006201 & 0.003101 & 1.738303 & 0.220797 \\
Error & 11 & 0.01962 & 0.001784 & & \\
\hline Total & 17 & 0.047641 & & & \\
\hline
\end{tabular}

In Table 4, the signal-to-noise values are calculated for each of the levels as well. Using these values, optimum levels could be identified. A level is selected for Population size to maximize its value with respect to other parameters. The levels of other parameters are not significantly different. Therefore, one of these levels could be selected desirably. Here again the levels with highest signal-to-noise ratio are selected. Therefore, the optimum levels are as follows: population size: 150; intersection rate: 0.7; and mutation probability: 0.3 .

\section{Table 4}

Mean Signal-To-Noise values for the levels of Genetic Parameters

\begin{tabular}{llll}
\hline Parameter & Level 1 & Level 2 & Level 3 \\
\hline Population size & -0.82944 & -0.82833 & -0.8271 \\
intersection Rate & -0.82863 & -0.82767 & -0.82858 \\
Mutation probability & -0.82899 & -0.82806 & -0.82783 \\
\hline
\end{tabular}

\section{Computational Results}

In this section, an example is provided and in the following the results of the sensitivity analysis are presented.

\subsection{Example}

Consider a financial market with 3 risky assets where their rates of return are considered as trapezoidal fuzzy numbers. An investor with an initial capital W1 $=10000$ joins the market. The investor plans to decide in connection with the two-period portfolio, in which each investment period is a year. The necessary data have been extracted from Zhang et al. (2012). The trapezoidal fuzzy numbers of the rate of return on assets in each of the periods are shown in Table 5.

Table 5

The Rate of Return on Assets as Trapezoidal Fuzzy Numbers

\begin{tabular}{lcc}
\hline & Period 1 & Period 2 \\
\hline Asset 1 & $(0.0361,0.1634,0.5521,1.7053)$ & $(0.0000,0.0819,0.2563,0.4565)$ \\
Asset 2 & $(0.0346,0.1118,0.2800,0.7781)$ & $(0.0048,0.1099,0.2968,0.4748)$ \\
Asset 3 & $(0.0241,0.0838,0.2057,0.3573)$ & $(0.0045,0.0845,0.2613,0.4325)$ \\
\hline
\end{tabular}

It is also assumed that the transaction cost of each share is equal to 0.003 , considered for each 3 shares in the same period. The minimum expected rate of return in Periods 1 and 2 is assumed, respectively, 
0.17 and 0.08. MATLAB is used to solve the developed algorithm problem. Also, the minimum transaction lot for each of the shares is set as 500 . The problem is resolved in the following modes:

Mode 1.Regardless of transaction cost of stocks and minimum transaction lots,

Mode 2.Regardless of transaction cost of stocks and with regard to minimum transaction lots,

Mode 3. With regard to transaction cost of stocks and regardless of minimum transaction lots,

Mode 4. With regard to transaction cost of stocks and minimum transaction lots.

The comparative results of the model solution are listed below. All solutions were possible and the solution time is about 30 seconds. In all cases:

$\mathrm{RN}:[0.17000 .0800]$

$\mathrm{W}:[1.1700 \mathrm{e}+041.2637 \mathrm{e}+04]$

The values of the fitness as well as the objective functions for different modes are provided in Table 6 .

\section{Table 6}

Fitness and Objective Functions Values in the Base Example in Different Modes

\begin{tabular}{lcc}
\hline & Fitness function & objective function \\
\hline Mode 1 & 1.1001 & .0954 \\
Mode 2 & 1.1032 & .0983 \\
Mode 3 & 1.1050 & .0998 \\
Mode 4 & 1.1079 & .1025 \\
\hline
\end{tabular}

From the results of Table 6 it follows that, with regard to each of the parameters of transaction cost of stocks and minimum transaction lots, the objective function problem gets worse. In other words, the semi-variance value enlarges. Note that although the objective function gets worse, the value of accumulated wealth and the rate of return in the periods remains constant. Note that return values are exactly equal to the minimum expected rate of return. Table 7 presents the values of variables y and the optimum portfolio.

\section{Table 7}

Solution to the problem in the base example in different modes

\begin{tabular}{ccc}
\hline & Variable y $\left(* 10^{15}\right)$ & Optimum Portfolio \\
\hline Mode 1 & {$[0.453 .060 .151 .342 .661 .58]$} & {$[0.130 .830 .040 .250 .470 .28]$} \\
Mode 2 & {$[0.972 .980 .852 .252 .460 .63]$} & {$[0.200 .620 .180 .420 .460 .12]$} \\
Mode 3 & {$[0.723 .080 .361 .562 .620 .56]$} & {$[0.170 .740 .090 .330 .550 .12]$} \\
Mode 4 & {$[1.863 .321 .761 .803 .201 .73]$} & {$\left[\begin{array}{lll}0.27 & 12: 4812: 250.270 .470 .26\end{array}\right]$} \\
\hline
\end{tabular}

\subsection{Sensitivity analysis of the minimum rate of return}

In this section, the results of the sensitivity analysis on the minimum rate of returns of the periods are presented. Note that here only the results of mode4 are considered where transactions cost as well as minimum transaction lots are included. The results of the sensitivity analysis are shown in Table 8 . The first column of this table represents the number of the problems; the second column represents the parameters of the problem that vary in different problems. The third to fifth columns represent the 
optimum parameters of each problem. Note that in this table, dash represents the impossibility of the solution.

Table 8

Sensitivity Analysis Parameters and Results

\begin{tabular}{|c|c|c|c|c|}
\hline & The expected rate $\left(r_{1}, r_{2}\right)$ & $\mathrm{RN}:\left[\mathrm{R}_{1} \mathrm{R}_{2}\right]$ & $\mathrm{W}:\left[\mathrm{W}_{1} \mathrm{~W}_{2}\right]$ & OBJ $\left(10^{-4}\right)$ \\
\hline 1 & .05 .02 & {$\left[\begin{array}{lll}0.1496 & 0.0752\end{array}\right]$} & [11496 12361] & 855 \\
\hline 2 & .08 .02 & {$\left[\begin{array}{lll}0.1496 & 0.0752\end{array}\right]$} & [11496 12361] & 855 \\
\hline 3 & .11 .02 & {$\left[\begin{array}{lll}0.1496 & 0.0752\end{array}\right]$} & [11496 12361] & 855 \\
\hline 4 & .14.02 & {$\left[\begin{array}{lll}0.1496 & 0.0752\end{array}\right]$} & [11496 12361] & 855 \\
\hline 5 & 17.02 & {$\left[\begin{array}{lll}0.1700 & 0.0748\end{array}\right]$} & [11700 12575] & 1002 \\
\hline 6 & 20.02 & {$\left[\begin{array}{lll}0.2000 & 0.0755\end{array}\right]$} & [12000 12906] & 1299 \\
\hline 7 & .23 .02 & - & - & - \\
\hline 8 & .05.04 & {$\left[\begin{array}{lll}0.1496 & 0.0752\end{array}\right]$} & [11496 12361] & 855 \\
\hline 9 & .08 .04 & {$\left[\begin{array}{lll}0.1496 & 0.0752\end{array}\right]$} & [11496 12361] & 855 \\
\hline 10 & 11.04 & {$\left[\begin{array}{lll}0.1496 & 0.0752\end{array}\right]$} & [11496 12361] & 855 \\
\hline 11 & .14.04 & {$\left[\begin{array}{lll}0.1496 & 0.0752\end{array}\right]$} & [11496 12361] & 855 \\
\hline 12 & .17.04 & {$\left[\begin{array}{lll}0.1700 & 0.0748\end{array}\right]$} & [11700 12575] & 1003 \\
\hline 13 & 20.04 & {$\left[\begin{array}{lll}0.2000 & 0.0755\end{array}\right]$} & [12000 12906] & 1298 \\
\hline 14 & 23.04 & - & - & - \\
\hline 15 & .05 .06 & {$\left[\begin{array}{lll}0.1496 & 0.0752\end{array}\right]$} & [11496 12361] & 855 \\
\hline 16 & 08.06 & {$\left[\begin{array}{lll}0.1496 & 0.0752\end{array}\right]$} & [11496 12361] & 855 \\
\hline 17 & 11.06 & {$\left[\begin{array}{lll}0.1496 & 0.0752\end{array}\right]$} & [11496 12361] & 855 \\
\hline 18 & 14.06 & {$\left[\begin{array}{lll}0.1496 & 0.0752\end{array}\right]$} & [11496 12361] & 855 \\
\hline 19 & 17.06 & {$\left[\begin{array}{lll}0.1700 & 0.0749\end{array}\right]$} & [11700 12575] & 1004 \\
\hline 20 & 20.06 & {$\left[\begin{array}{lll}0.2000 & 0.0754\end{array}\right]$} & [12000 12905] & 1299 \\
\hline 21 & .23 .06 & - & - & - \\
\hline 22 & .05 .08 & {$\left[\begin{array}{lll}0.1619 & 0.0800\end{array}\right]$} & [11618 12547] & 965 \\
\hline 23 & .08 .08 & {$\left[\begin{array}{ll}0.1618 & 0.0800\end{array}\right]$} & [11618 12547] & 963 \\
\hline 24 & .11.08 & {$\left[\begin{array}{lll}0.1618 & 0.0800\end{array}\right]$} & [11618 12547] & 964 \\
\hline 25 & .14 .08 & {$\left[\begin{array}{lll}0.1620 & 0.0800\end{array}\right]$} & [11620 12549] & 964 \\
\hline 26 & .17.08 & {$\left[\begin{array}{lll}0.1700 & 0.0800\end{array}\right]$} & [11700 12636] & 1026 \\
\hline 27 & 20.08 & - & - & - \\
\hline 28 & .23 .08 & - & - & - \\
\hline
\end{tabular}

\section{Conclusion}

The present study has examined a multi-period portfolio selection problem which was based on a mean semi-variance model and had to cope with transaction costs and transaction lots. To approximate the problem to the dominant conditions of the market, and given the nature of the parameters which were often under vagueness and uncertainty, the problem has been studied in fuzzy environment. The parameters of the rate of returns on assets have been considered as trapezoidal fuzzy numbers. With multi-period portfolio as a newly-emerged issue, the need for certain factors was felt to make the resulted model more realistic. Among these factors, transaction costs as well as transaction lots were considered important factors on optimal portfolio selection. The problem has been solved using genetic algorithm under the assumption of both states of presence and absence of each of the constraints including transaction costs and transaction lots. The results of the model were presented with variations of minimum expected rate of programming periods.

\section{Future Studies}

To extend the findings, other meta-heuristic algorithms such as simulated annealing, particle swarm optimization, or harmony search could be designed for the problem and a comparison between the obtained results and the results of GA for problems with different sizes could be proposed. In addition, other measures may enter the model and as a result a multi-objective optimization model could be investigated and solved. For example, measures such as rate of return or skewed could be maximized and the risk could be minimized. 


\section{References}

WagnerWayne, H. (1990). The measurement and control of trading costs.Financial Analysts Journal, 46(6), 73-80.

Calafiore, G. C. (2008). Multi-period portfolio optimization with linear control policies. Automatica, 44(10), 2463-2473.

Celikyurt, U., \& Özekici, S. (2007). Multiperiod portfolio optimization models in stochastic markets using the mean-variance approach. European Journal of Operational Research, 179(1), 186-202.

Giove, S., Funari, S., \& Nardelli, C. (2006). An interval portfolio selection problem based on regret function. European Journal of Operational Research,170(1), 253-264.

Golberg, D. E. (1989). Genetic algorithms in search, optimization, and machine learning. Addion Wesley, 1989.

Gülpınar, N., \& Rustem, B. (2007). Worst-case robust decisions for multi-period mean-variance portfolio optimization. European Journal of Operational Research, 183(3), 981-1000.

Gupta, P., Mehlawat, M. K., \& Saxena, A. (2008). Asset portfolio optimization using fuzzy mathematical programming. Information Sciences, 178(6), 1734-1755.

Li, D., \& Ng, W. L. (2000). Optimal Dynamic Portfolio Selection: Multiperiod Mean-Variance Formulation. Mathematical Finance, 10(3), 387-406.

Li, J., \& Xu, J. (2013). Multi-objective portfolio selection model with fuzzy random returns and a compromise approach-based genetic algorithm.Information Sciences, 220, 507-521.

Liu, Y. J., \& Zhang, W. G. (2013). Fuzzy portfolio optimization model under real constraints. Insurance: Mathematics and Economics, 53(3), 704-711.

Liu, Y. J., Zhang, W. G., \& Xu, W. J. (2012). Fuzzy multi-period portfolio selection optimization models using multiple criteria. Automatica, 48(12), 3042-3053.

Mansini, R., \& Speranza, M. G. (1999). Heuristic algorithms for the portfolio selection problem with minimum transaction lots. European Journal of Operational Research, 114(2), 219-233.

Markowitz, H. (1959). Portfolio Selection: Efficient Diversification of Investments. John Wiley, New York.

Sadjadi, S. J., Seyedhosseini, S. M., \& Hassanlou, K. (2011). Fuzzy multi period portfolio selection with different rates for borrowing and lending. Applied Soft Computing, 11(4), 3821-3826.

Sun, J., Fang, W., Wu, X., Lai, C. H., \& Xu, W. (2011). Solving the multi-stage portfolio optimization problem with a novel particle swarm optimization. Expert Systems with Applications, 38(6), 67276735.

Takano, Y., \& Gotoh, J. Y. (2011). Constant rebalanced portfolio optimization under nonlinear transaction costs. Asia-Pacific Financial Markets, 18(2), 191-211.

Wei, S. Z., \& Ye, Z. X. (2007). Multi-period optimization portfolio with bankruptcy control in stochastic market. Applied Mathematics and Computation, 186(1), 414-425.

Xia, Y., Liu, B., Wang, S., \& Lai, K. K. (2000). A model for portfolio selection with order of expected returns. Computers \& Operations Research, 27(5), 409-422.

Yu, J. R., \& Lee, W. Y. (2011). Portfolio rebalancing model using multiple criteria. European Journal of Operational Research, 209(2), 166-175.

Zadeh, L. A. (1965). Fuzzy sets. Information and control, 8(3), 338-353.

Zhang, W. G., Liu, Y. J., \& Xu, W. J. (2012). A possibilistic mean-semivariance-entropy model for multiperiod portfolio selection with transaction costs. European Journal of Operational Research, 222(2), 341-349.

Zhang, X. L., \& Zhang, K. C. (2009). Using genetic algorithm to solve a new multi-period stochastic optimization model. Journal of computational and applied mathematics, 231(1), 114-123. 